\title{
Childhood asthma is associated with COPD and known asthma variants in COPDGene: a genome-wide association study
}

Lystra P. Hayden ${ }^{1,2^{*}}$ (D), Michael H. Cho ${ }^{2,3}$, Benjamin A. Raby ${ }^{1,2,3}$, Terri H. Beaty ${ }^{4}$, Edwin K. Silverman²,3, Craig P. Hersh ${ }^{2,3}$ and on behalf of the COPDGene Investigators

\begin{abstract}
Background: Childhood asthma is strongly influenced by genetics and is a risk factor for reduced lung function and chronic obstructive pulmonary disease (COPD) in adults. This study investigates self-reported childhood asthma in adult smokers from the COPDGene Study. We hypothesize that childhood asthma is associated with decreased lung function, increased risk for COPD, and that a genome-wide association study (GWAS) will show association with established asthma variants.
\end{abstract}

Methods: We evaluated current and former smokers ages 45-80 of non-Hispanic white (NHW) or African American (AA) race. Childhood asthma was defined by self-report of asthma, diagnosed by a medical professional, with onset at $<16$ years or during childhood. Subjects with a history of childhood asthma were compared to those who never had asthma based on lung function, development of COPD, and genetic variation. GWAS was performed in NHW and AA populations, and combined in meta-analysis. Two sets of established asthma SNPs from published literature were examined for association with childhood asthma.

Results: Among 10,199 adult smokers, 730 (7\%) reported childhood asthma and 7493 (73\%) reported no history of asthma. Childhood asthmatics had reduced lung function and increased risk for COPD (OR 3.42, 95\% Cl 2.81-4.18). Genotype data was assessed for 8031 subjects. Among NHWs, 391(7\%) had childhood asthma, and GWAS identified one genome-wide significant association in KIAA1958 (rs59289606, $p=4.82 \times 10^{-8}$ ). Among AAs, 339 (12\%) had childhood asthma. No SNPs reached genome-wide significance in the AAs or in the meta-analysis combining NHW and AA subjects; however, potential regions of interest were identified. Established asthma SNPs were examined, seven from the NHGRI-EBI database and five with genome-wide significance in the largest pediatric asthma GWAS. Associations were found in the current childhood asthma GWAS with known asthma loci in IL1RL1, IL13, LINC01149, near GSDMB, and in the C110rf30-LRRC32 region (Bonferroni adjusted $p<0.05$ for all comparisons).

Conclusions: Childhood asthmatics are at increased risk for COPD. Defining asthma by self-report is valid in populations at risk for COPD, identifying subjects with clinical and genetic characteristics known to associate with childhood asthma. This has potential to improve clinical understanding of asthma-COPD overlap (ACO) and enhance future research into ACO-specific treatment regimens.

Trial registration: ClinicalTrials.gov, NCT00608764 (Active since January 28, 2008).

Keywords: Childhood asthma, Genome-wide association study, Chronic obstructive pulmonary disease, Lung function, Genetic epidemiology

\footnotetext{
* Correspondence: Lystra.Hayden@childrens.harvard.edu

${ }^{1}$ Division of Respiratory Diseases, Boston Children's Hospital, Boston, MA, USA

${ }^{2}$ Channing Division of Network Medicine, Brigham and Women's Hospital,

181 Longwood Avenue, Boston, MA 02115, USA

Full list of author information is available at the end of the article
}

(c) The Author(s). 2018 Open Access This article is distributed under the terms of the Creative Commons Attribution 4.0 International License (http://creativecommons.org/licenses/by/4.0/), which permits unrestricted use, distribution, and reproduction in any medium, provided you give appropriate credit to the original author(s) and the source, provide a link to the Creative Commons license, and indicate if changes were made. The Creative Commons Public Domain Dedication waiver (http://creativecommons.org/publicdomain/zero/1.0/) applies to the data made available in this article, unless otherwise stated. 


\section{Background}

Asthma is the most common chronic disease of childhood, affecting $8.4 \%$ of children in the United States [1]. Childhood asthma is a genetically distinct asthma subtype, with estimated heritability of $68-92 \%$ [2-10]. Asthma is a known risk factor for development of reduced lung function and chronic obstructive pulmonary disease (COPD) in adults [11-14]. Asthmatics are often excluded from COPD studies, and thus information on the mechanism of disease and appropriate treatments for asthma-COPD overlap (ACO) remains limited [15].

We have previously examined self-reported history of childhood asthma and ACO in the COPDGene Study, a cohort of more than 10,000 adult smokers with and without COPD. We have shown that a combined history of childhood pneumonia with childhood asthma is a risk factor for developing COPD [16]. We demonstrated that that ACO subjects were younger with a lower lifetime smoking intensity, and that both childhood asthmatics and ACO subjects have increased airways disease on chest computed tomography scan [17-19]. Longitudinal analysis has shown that early-life asthmatics do not have increased rates of lung function decline despite their increased exacerbation frequency [20]. We have not previously examined childhood asthma as an independent risk factor for COPD in this population.

As interest in the long-term outcomes of early-life asthmatics has expanded, a recurring question has risen about the validity of using self-reported asthma history in large adult cohorts recruited for genetic epidemiology studies $[21,22]$. This has been particularly important when trying to understand Asthma-COPD Overlap (ACO), as epidemiologic studies of COPD, an adult disease, rely on self-reported history of asthma early in life both for exclusion criteria and for analysis [15, 23]. Our current investigation examines self-reported childhood asthma in adult smokers from the COPDGene Study, to see if they share similar phenotypes and genotypes with those seen in asthmatic subjects from prior studies, including published GWAS [2, 3, 24]. Prior GWAS have implicated genetic susceptibility specific to childhood asthma, including variants in ORMDL3/GSDMB, IL1RL1, IL33, and $R A D 50$ [4, 7, 24]. We hypothesize that self-reported history of childhood asthma will be associated with decreased lung function and increased risk for COPD in adult smokers, and that a genome-wide association study (GWAS) will show an increased prevalence of known asthma variants among childhood asthmatics, compared to those subjects who never had asthma.

\section{Methods}

\section{Subjects}

We evaluated 10,199 current and former adult smokers enrolled in the COPDGene Study between 2008 and
2011 (August 31, 2016 dataset). The COPDGene Study is a multicenter, observational study designed to identify genetic and environmental factors associated with COPD. Subjects included were of non-Hispanic (NHW) white or African American (AA) race, between 45 and 80 years of age, and had at least a 10 pack-year history of smoking. We excluded subjects with lung disease other than asthma or COPD, or those who were nonsmokers. Subjects were recruited at 21 clinical sites within the U.S. Each site received institutional review board approval and each participant provided informed consent [25]. Details of the study protocol and data forms are available at www.copdgene.org [25, 26].

\section{Data collection}

Subject responses to a modified American Thoracic Society Respiratory Epidemiology Questionnaire were used to collect asthma history [26, 27]. A standardized spirometry protocol pre and post-albuterol was completed (ndd EasyOne Spirometer, Zurich, Switzerland). DNA extracted from blood samples was genotyped using HumanOmniExpress arrays (Illumina, San Diego, CA). DNA and single nucleotide polymorphism (SNP) data underwent standard quality control measures $[25,28$, 29]. Imputation used 1000 Genomes Phase I v3 reference panels (hg19) to obtain additional genotypes with $\mathrm{MaCH}$ and minimac (exomeChip pipelineV1.4) [29-32]. Imputation quality was assessed using Rsq, and SNPs with Rsq $>0.3$ were considered to be of acceptable quality. COPDGene datasets are publicly available (dbGaP accession number phs000179.v1.p1).

\section{Case identification}

Asthma history was assessed by questionnaire response. Subjects were asked if they had ever had asthma, at what age it started, and if it was diagnosed by a doctor or other health professional. Childhood asthma was defined as self-report of asthma diagnosed by a health professional with age of onset at $<16$ years or as a child with exact age not known [5, 16, 20,33]. Subjects were classified as never having asthma if they responded "No" to asthma history on the questionnaire. As in previous COPDGene publications, COPD was defined as Global Initiative for Chronic Obstructive Lung Disease (GOLD) 2007 spirometry grades 2-4, corresponding to post-bronchodilator forced expiratory volume in the first second $\left(\mathrm{FEV}_{1}\right)$ to forced vital capacity (FVC) ratio $<0.7$ with $\mathrm{FEV}_{1}<80 \%$ predicted [16-18, 20, 34]. Control smokers had normal spirometry, defined as $\mathrm{FEV}_{1} /$ $\mathrm{FVC} \geq 0.7$ and $\mathrm{FEV}_{1} \geq 80 \%$.

\section{Statistical analysis}

Subjects with childhood asthma were compared to subjects who never had asthma on measures of lung function 
and development of COPD. Subjects with missing or unclassifiable responses were removed from the specific analysis. Statistical analysis used R v3.1.1. Single variable analysis used chi-square tests, Wilcoxon rank sum tests, or t-tests. Multivariable regression analysis was performed, all models were adjusted for number of pack years of smoking history. COPD and $\mathrm{FEV}_{1} / \mathrm{FVC}$ models were additionally adjusted for gender, age at enrollment, and race. The $\mathrm{FEV}_{1} / \mathrm{FVC}$ model was also adjusted for height; percent predicted $\mathrm{FEV}_{1}$ and $\mathrm{FVC}$ values have these factors accounted for in the baseline variable thus no adjustment was indicated. Logistic regression reported odds ratio (OR) with 95\% confidence interval $(\mathrm{CI})$ and linear regression reported absolute difference $(\beta)$ with standard error (SE).

GWAS were performed comparing those with history of childhood asthma to those who never had asthma using PLINK 1.90 [35]. GWAS were performed in the NHW and AA populations separately using logistic regression adjusted for sex and principal components (PC) for genetic ancestry [28]. SNPs were considered to reach genome-wide significance at the threshold of $p \leq 5 \times 10^{-8}$, and regions of interest were identified at near genomewide significance with $p \leq 1 \times 10^{-6}[36,37]$. The degree of genomic inflation after PC adjustment was assessed [38]. Results from the NHW and AA populations were combined in a fixed effects meta-analysis with inverse variance weighting $[35,39]$.

\section{Comparison to published asthma GWAS}

The childhood asthma GWAS results were examined for association with established asthma SNPs derived from the National Human Genome Research Institute - European Bioinformatics Institute (NHGRI-EBI) Catalog of published genome-wide association studies (Sept 28, 2017 search, https://www.ebi.ac.uk/gwas/search) [2, 3]. A search for the disease/trait "asthma" identified 85 studies, with 600 SNP associations. Eight SNPs were identified in more than one NHGRI-EBI catalog study, and were considered established asthma SNPs: rs10197862 in IL1RL1, rs1837253 near TSLP, rs2244012 in RAD50, rs1295686 in IL13, rs7130588 near the C11orf30-LRRC32 region, rs3894194 in GSDMA, rs2305480 and rs11078927 in GSDMB $[7,40-50]$. Two GSDMB SNPs were in high linkage disequilibrium $\left(r^{2}>0.8\right)$. We selected the SNP that was genotyped in our population, rs2305480, for inclusion, and rs11078927 was excluded, leaving seven established asthma SNPs. These seven established asthma SNPs were examined for association with childhood asthma in the current GWAS, with a Bonferroni correction for seven tests performed, and a significance level of 0.05. Hypergeometric testing was used to calculate the likelihood that the established asthma SNPs were over-represented in this sample.
The childhood asthma GWAS results were additionally examined for association with the five genetic loci found to be associated with pediatric asthma in the largest pediatric asthma GWAS to date (8976 cases, 18,399 controls) from the Trans-National Asthma Genetic Consortium (TAGC): rs4988958 in IL1RL1, rs1295685 in IL13, rs2596464 in LINC01149, rs12551256 in IL33, rs8069176 near GSDMB [24]. These five TAGC pediatric asthma SNPs were examined for association with childhood asthma in the current GWAS, with a Bonferroni correction for five tests performed, and a significance level of 0.05 .

\section{Results}

\section{Subject classification}

Of 10,199 subjects in the COPDGene study, 730 (7\%) had childhood asthma and 7493 (73\%) were control subjects without childhood asthma (Table 1). There were 1976 subjects removed from the analysis: 52 with responses to the childhood asthma questions that were not classifiable, 1229 who reported a history of asthma that did not start in childhood, and 695 who reported they did not know if they had asthma (Additional file 1: Figure S1).

\section{Subject characteristics}

Compared to subjects without childhood asthma, those with history of childhood asthma were younger and more likely to be AA. Subjects with childhood asthma had increased odds of developing COPD (OR 3.42, 95\% CI 2.81-4.18) (Table 2). When compared to those without childhood asthma, adult smokers with asthma during childhood also had reduced lung function measured by $\mathrm{FEV}_{1}, \mathrm{FVC}$ and $\mathrm{FEV}_{1} / \mathrm{FVC}(p<0.001$ for all comparisons).

\section{GWAS}

Genotype data was assessed in 8031 subjects who met case/control criteria (Additional file 1: Figure S1). Among the 5364 NHWs, there were 385 (7\%) childhood asthma

Table 1 Characteristics of childhood asthma subjects compared to subjects without asthma in COPDGene

\begin{tabular}{llll}
\hline & $\begin{array}{l}\text { Childhood Asthma } \\
N=730\end{array}$ & $\begin{array}{l}\text { Never Asthma } \\
N=7493\end{array}$ & $\begin{array}{l}P \text {-value } \\
\text { Male gender (\%) }\end{array}$ \\
Mean age, year (SD) & $388(53 \%)$ & $4255(57 \%)$ & 0.06 \\
Non-Hispanic white (\%) $^{\mathrm{a}}$ & $38(9)$ & $60(9)$ & $<0.001$ \\
African American (\%) $^{\mathrm{a}}$ & $339(46 \%)$ & $5075(68 \%)$ & $<0.001$ \\
Pack-years of smoking & $43(25)$ & $2418(32 \%)$ & $<0.001$ \\
(SD) $^{\mathrm{b}}$ & & $44(25)$ & 0.09 \\
Current smoking (\%) $^{\mathrm{a}}$ & $410(56 \%)$ & $4041(54 \%)$ & 0.26 \\
History of hay fever (\%) $^{\mathrm{a}}$ & $385(53 \%)$ & $1727(23 \%)$ & $<0.001$ \\
\hline
\end{tabular}

Univariate analysis with ${ }^{\mathrm{a}} \mathrm{Chi}$-square ${ }^{\mathrm{b}}$ Wilcoxon rank sum test ${ }^{\mathrm{c}} \mathrm{t}$-test 
Table 2 COPD and lung function in subjects with childhood asthma compared to never asthma subjects

\begin{tabular}{|c|c|c|c|c|c|}
\hline & \multirow{3}{*}{$\begin{array}{l}\text { Childhood } \\
\text { Asthma } \\
N=730\end{array}$} & \multirow{3}{*}{$\begin{array}{l}\text { Never } \\
\text { Asthma } \\
N=7493\end{array}$} & \multicolumn{3}{|c|}{ Impact of Childhood Asthma } \\
\hline & & & & & \\
\hline & & & OR & $95 \% \mathrm{Cl}$ & $P$-value ${ }^{a}$ \\
\hline \multirow[t]{2}{*}{$\operatorname{COPD}(\%)^{\mathrm{b}, \mathrm{d}, \mathrm{e}}$} & $341(47 \%)$ & $2303(31 \%)$ & 3.42 & $(2.81,4.18)$ & $<0.001$ \\
\hline & & & $\beta$ & SE & $P$-value \\
\hline $\mathrm{FEV}_{1}$ post-bronchodilator $\%$ predicted $(\mathrm{SD})^{\mathrm{c}, \mathrm{d}}$ & $69 \%(25)$ & $80 \%(26)$ & -10.44 & 0.92 & $<0.001$ \\
\hline FVC post-bronchodilator \% predicted (SD) $)^{\mathrm{c}, \mathrm{d}}$ & $83 \%(19)$ & $89 \%(18)$ & -6.01 & 0.68 & $<0.001$ \\
\hline $\mathrm{FEV}_{1} / \mathrm{FVC}$ post-bronchodilator (SD) $)^{\mathrm{c}, \mathrm{d}, \mathrm{e}, \mathrm{f}}$ & $0.64(0.16)$ & $0.68(0.16)$ & -0.06 & 0.01 & $<0.001$ \\
\hline
\end{tabular}

Abbreviations: COPD chronic obstructive pulmonary disease; $F E V$, forced expiratory volume in the first second; $S D$ standard deviation; FVC forced vital capacity. ${ }^{a}$ Each row is a separate model: ${ }^{b}$ Logistic regression with odds ratio (OR), 95\% confidence interval $(\mathrm{Cl})$; ${ }^{c}$ Linear regression with beta coefficient $(\beta)$, standard error (SE). Covariates: ${ }^{d}$ pack years; ${ }^{e}$ gender, age at enrollment, race; ${ }^{f}$ height

cases and 4979 (93\%) controls without childhood asthma. Among the 2667 AAs, there were 325 (12\%) childhood asthma cases and 2342 (88\%) controls. NHW and AA GWAS included all SNPs with minor allele frequency (MAF) $\geq 5 \%$, Quantile-Quantile (QQ) and Manhattan plots including can be viewed in Additional file 1: Figure S2 and S3. Lambda values were 1.01 in both NHW and AA populations. Meta-analysis included all SNPs with MAF $\geq 1 \%$, with a lower MAF cutoff used to account for the more modest correlation of variants between ancestries; QQ and Manhattan plots are in Additional file 1: Figure S4 [39, 51].

In the NHW childhood asthma GWAS, one SNP reached the level of genome-wide significance, rs59289606 located in the gene KIAA1958 $\left(p=4.82 \times 10^{-8}\right)$ (Table 3, Fig. 1, Additional file 1: Figure S2). An additional region of interest was identified in PDZD2 with three SNPs approaching genome-wide significance $(p=3.9-$ $7.80 \times 10^{-7}$ ) (Additional file 1: Figure S5). In the AA childhood asthma GWAS, no SNPs reached the level of genome-wide significance, however, regions of interest were identified in FLJ12825 $\left(p=1.75 \times 10^{-7}\right)$ and PHF14 $\left(p=4.94 \times 10^{-7}\right)$ (Additional file 1: Figure S6). Metaanalysis combined the NHW and AA results from this study. No meta-analysis SNPs reached the level of genome-wide significance. However, a region of interest was identified in SCHIP1 and its read through transcript IQCJ-SCHIP1 with 14 SNPs approaching genome-wide significance $\left(p=2.39-7.84 \times 10^{-7}\right)$ (Fig. 1).

\section{Association testing of established asthma variants}

Seven NHGRI-EBI SNPs previously known to be associated with asthma were extracted from the current GWAS results (Table 4). Among the NHW population, the childhood asthma GWAS found association with a known asthma variants in IL1RL1 (rs10197862, adjusted $p=0.011)$ and approached significance in GSDMB (rs2305480, adjusted $p=0.060$ ) and near the C11orf30LRRC32 region (rs7130588, adjusted $p=0.054$ ) (Additional file 1: Figure S7). The meta-analysis of NHW and AA subjects in our childhood asthma GWAS found association with known asthma variants in IL1RL1 (rs10197862, adjusted $p=0.042$ ), in IL13 (rs1295686, adjusted $p=0.043$ ), and near the C11orf30-LRRC32 region (rs7130588, adjusted $p=0.005$ ) (Additional file 1: Figure S8). There is agreement in direction of effect in these four associated or near associated SNPs in both NHW and AA populations as well as with prior published GWAS [7, 40, 44, 45, 49, 50]. Hypergeometric testing showed that when selecting seven SNPs from the meta-analysis population, the probability of having one or more SNP significant at this level was $p=0.034$. Among the meta-analysis population, when selecting seven SNPs, the probability of having three or more SNP significant at this level was $p=1.21 \times 10^{-05}$.

Five SNPs associated with pediatric asthma in the TAGC GWAS were examined within the current GWAS results (Additional file 1: Table S1). Reported $p$-values were Bonferroni corrected for five tests, with a significance level of 0.05. Among the NHW population, the childhood asthma GWAS found association with TAGC pediatric asthma SNPs in IL1RL1 (rs4988958, adjusted $p$ $=0.002)$, LINC01149 (rs2596464, adjusted $p=0.021$ ), and near the GSDMB region (rs8069176, adjusted $p=$ 0.041). The meta-analysis of NHW and AA subjects in out childhood asthma GWAS found association with IL1RL1 (rs4988958, adjusted $p=0.035$ ) and LINC01149 (rs2596464, adjusted $p=0.017$ ).

\section{Discussion}

This analysis is the first to demonstrate that a self-reported history of childhood asthma is a valid method for defining a population that phenotypically and genetically represent asthmatic subjects among a cohort of adult smokers at risk for COPD. When compared to those who never had asthma, self-reported childhood asthmatics were younger at study enrollment, more likely to be of AA race, and had decreased lung function with greater odds of developing COPD. Three of seven established NHGRI-EBI asthma SNPs and three of five pediatric asthma SNPs from the TAGS GWAS were associated with self-reported childhood 
Table 3 Top SNPs from childhood asthma GWAS in COPDGene $e^{e}$

\begin{tabular}{|c|c|c|c|c|c|c|c|c|c|c|}
\hline & Locus & SNP & Effect Allele & OR & Rsq & Freq (\%) & & P-value ${ }^{b, d}$ & Gene Symbol & Gene Name \\
\hline $\mathrm{NHW}^{\mathrm{a}}$ & $9 q 32$ & rs59289606 & A & 2.06 & 0.38 & $20 \%$ & & $4.82 \mathrm{E}-08$ & KIAA1958 & \\
\hline$(8,900,203$ SNPs) & $5 \mathrm{p} 13.3$ & rs439399 & C & 1.52 & 0.99 & $22 \%$ & & $3.90 \mathrm{E}-07$ & PDZD2 & PDZ domain containing 2 \\
\hline$\overline{A A^{a}}$ & $12 q 13.13$ & rs7315121 & $T$ & 2.90 & 0.45 & $7 \%$ & & $1.75 \mathrm{E}-07$ & FLI12825 & uncharacterized LOC440101 \\
\hline \multirow[t]{2}{*}{$(15,374,350$ SNPs) } & $7 p 21.3$ & rs56317450 & A & 2.11 & 0.79 & $8 \%$ & & 4.94E-07 & PHF14 & PHD finger protein 14 \\
\hline & Locus & SNP & Effect Allele & OR & $\begin{array}{l}\text { Rsq } \\
\text { NHW, AA }\end{array}$ & $\begin{array}{l}\text { Freq (\%) } \\
\text { NHW, AA }\end{array}$ & $I^{2}$ & P-value ${ }^{c, d}$ & Gene Symbol & Gene Name \\
\hline $\begin{array}{l}\text { Meta-analysis } \\
(7,658,992 \text { SNPs) }\end{array}$ & $3 q 25.32-q 25.33$ & rs4679858 & G & 1.48 & $0.99,0.98$ & $14 \%, 12 \%$ & 0 & 2.39E-07 & $\begin{array}{l}\text { SCHIP1 } \\
\text { IQCJ-SCHIP1 }\end{array}$ & $\begin{array}{l}\text { schwannomin interacting } \\
\text { protein } 1 \& \text { the } \\
\text { readthrough }\end{array}$ \\
\hline
\end{tabular}

Abbreviations: GWAS genome-wide association study; NHW Non-Hispanic Whites; AA African American; SNP single nucleotide polymorphism; OR odds ratio of effect allele; Rsq estimation of imputation quality; Freq frequency of effect allele; $I^{2}$ heterogeneity index; ${ }^{a}$ Each population was run as an independent analysis, and then combined in the meta-analysis: ${ }^{b}$ Logistic regression based on case control status; ${ }^{c}$ Fixed effect meta-analysis weighted by inverse variance. ${ }^{d}$ Adjusted for sex, genetic ancestry. ${ }^{e}$ Includes the top SNP from each region with GWAS P-value $\leq 1 \times 10-6$

asthma, including SNPs in IL1RL1, IL13, near the C11orf30-LRRC32 region, in LINC01149, and near GSDMB. Additionally, GWAS identified one variant in KIAA1958 that was associated with childhood asthma among NHWs with genome-wide significance. Regions of interest were identified at near genome-wide significance among NHWs in PDZD2, among AAs in FLJ12825 and PHF14, and on meta-analysis in SCHIP1 and its read-through transcript IQCJ-SCHIP1.

There has been a growing interest in the risk of early life asthmatics for developing COPD, and thus ACO, in adulthood [15]. It has been proposed that in some childhood asthmatics, the risk for COPD is the result of the lungs never achieving their expected growth and development in early adulthood [11, 12, 16, 20, 52, 53]. Normal decline in lung function can lead to COPD since expected maximal $\mathrm{FEV}_{1}$ is never attained. ACO has been recognized as a distinct COPD subtype, with elevated risk for exacerbations, increased health-care burden, and different potential treatment modalities [54]. Research into the mechanisms of disease and genetic susceptibility for ACO subjects has been limited by the traditional exclusion of asthmatic subjects from large COPD studies [15]. Studies of COPD use spirometry as the accepted COPD definition; however, ACO research has been complicated by disagreement on a standard definition for asthma and therefore ACO $[15,34,54-56]$. COPD cohorts often include older adults and in many cases it is not possible to confirm early-life diagnosis of asthma by Global Initiative for Asthma (GINA) spirometry guidelines or by physician records $[55,57]$. Once COPD has been diagnosed, it is difficult to use bronchodilator reactivity to define asthma, as this can also be a feature of COPD. Use of self-reported history of asthma has raised concern due to the theoretical risk of misclassification bias [58].

This study confirms that childhood asthmatics who smoke are at increased risk for developing low lung function and COPD as adults, when compared to smokers who never had asthma. This investigation supports self-reported diagnosis of asthma history as a valid method of identifying early-life asthmatics, and a population of ACO subjects, in large population cohorts at risk for COPD. This will be particularly important as researchers further examine the genetic epidemiology of ACO.

There have been a number of prior asthma GWAS conducted in populations of asthmatic subjects, beginning with the GABRIEL Consortium in 2007, which focused on populations of European ancestry, and continuing through the recent TAGC GWAS, a meta-analysis in ethnically diverse populations including 23,948 cases and 118,538 controls; the TAGS GWAS included a pediatric subgroup meta-analysis with 8976 cases and 18,399 controls $[4,24]$. These asthma GWAS have used a range of asthma definitions, including physician diagnosis in GABRIEL, electronic medical record information in eMERGE, and physicians' diagnosis and/or standardized questionnaires in the TAGC $[4,24,47]$. A number of prior GWAS have identified distinct genetic susceptibility for pediatric onset asthma, particularly implicating ORLDM3/ GSDMB, IL1RL1, and IL13, which were all found to have association with childhood asthma in the current analysis [4, 5, 6, 7, 24, 59]. C11orf30-LRRC3, which also has association in this GWAS, has been associated with in pediatric asthma previously, though in prior GWAS the primary link with asthma has been in the setting of allergic disease [33, 60].

This study examined association with seven established asthma SNPs, selected as they were the only SNPs reported by more than one study among 85 studies in the NHGRI-EBI GWAS catalog, and five SNPs from the largest pediatric GWAS to date from the TAGC $[2,3,24]$. Five genes were found to be associated with self-reported childhood asthma in COPDGene: IL1RL1, IL13, LINC01149, near GSDMB, and in the C11orf30-LRRC32 region. IL1RL1 in the $2 \mathrm{q} 12.1$ region is thought to be involved in T-helper cell type 2 (TH2) inflammation including 

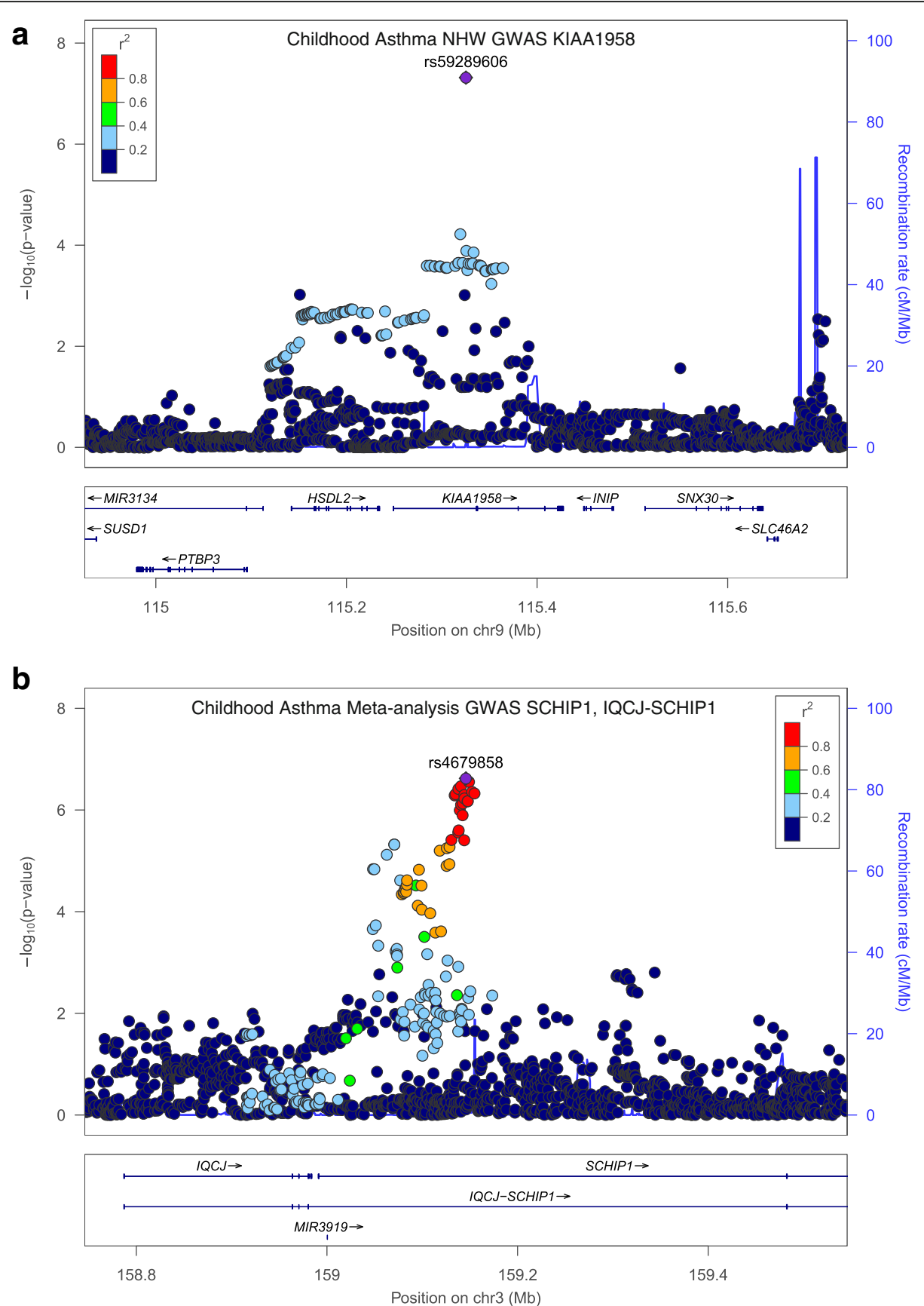

Fig. 1 LocusZoom Plot of childhood asthma GWAS variants a from non-Hispanic whites in KIAA1958 and $\mathbf{b}$ from the meta-analysis in the region near SCHIP1 and its read through transcript IQCJ-SCHIP1

eosinophil activation [42, 44-46, 61-64]. IL13 is an immunoregulatory cytokine produced by $\mathrm{TH} 2$ cells that is critical to the pathogenesis of allergic asthma, operating through mechanisms independent of IgE and eosinophils [65]. GSDMB in the established 17q21 childhood asthma risk region is potentially involved in pathogenesis via epithelial cell pyroptosis $[4,7,41,44,47,49,50,66]$. In asthmatics, the C11orf30-LRRC32 region is associated with total serum IgE levels [67]. We did not see evidence of association from three of the seven established NHGRI-EBI asthma SNPs, those found in TSLP, RAD50, and GSDMA. TSLP has a role in TH2 cell responses associated with inflammatory diseases including asthma and COPD [65]. RAD50 has been implicated in allergic airway inflammation, potentially vial regulation of $\mathrm{TH} 2$ cytokine genes, though the exact mechanism remains to be elucidated 
Table 4 Associations with NHGRI-EBI asthma SNPs in COPDGene childhood asthma GWAS

\begin{tabular}{|c|c|c|c|c|c|c|c|c|c|}
\hline$\overline{\mathrm{NHW}^{\mathrm{a}}}$ & Gene & SNP & Locus & Effect Allele & OR & Rsq & Freq (\%) & P-value $e^{b, d}$ & Adj P-value $^{e}$ \\
\hline \multirow[t]{7}{*}{ (385 cases, 4979 controls) } & IL1RL1 & rs10197862 ${ }^{f}$ & $2 q 12.1$ & A & 1.45 & 1.00 & 0.85 & 0.002 & 0.011 \\
\hline & TSLP & rs1837253 & $5 q 22.1$ & $\mathrm{~T}$ & 1.07 & & 0.75 & 0.414 & 1.000 \\
\hline & RAD50 & rs $2244012^{f}$ & $5 q 31.1$ & G & 1.05 & & 0.78 & 0.579 & 1.000 \\
\hline & $1 L 13$ & rs1295686 & $5 q 31.1$ & T & 1.22 & & 0.80 & 0.026 & 0.180 \\
\hline & C11orf30-LRRC32 & rs7130588 & $11 q 13.5$ & G & 1.23 & & 0.64 & 0.008 & 0.054 \\
\hline & GSDMB & rs2305480 & $17 q 21.1$ & G & 1.22 & & 0.44 & 0.009 & 0.060 \\
\hline & GSDMA & rs3894194 & $17 q 21.1$ & $A$ & 1.18 & 0.94 & 0.47 & 0.029 & 0.201 \\
\hline $\mathbf{A A}^{\mathrm{a}}$ & Gene & SNP & Locus & Effect Allele & OR & Rsq & Freq (\%) & P-value ${ }^{b, d}$ & Adj P-value \\
\hline \multirow[t]{7}{*}{ (325 cases, 2342 controls) } & ILIRLI & rs10197862 $2^{f}$ & $2 q 12.1$ & A & 1.10 & 0.98 & 0.74 & 0.344 & 1.000 \\
\hline & TSLP & rs18372539 & $5 q 22.1$ & C & 1.11 & & 0.28 & 0.283 & 1.000 \\
\hline & RAD50 & rs $2244012^{f}$ & $5 q 31.1$ & G & 1.05 & & 0.57 & 0.603 & 1.000 \\
\hline & $1 L 13$ & $\operatorname{rs} 1295686^{f}$ & $5 q 31.1$ & T & 1.16 & & 0.64 & 0.102 & 0.717 \\
\hline & C11orf30-LRRC32 & rs71305889 & $11 \mathrm{q} 13.5$ & G & 1.23 & & 0.80 & 0.035 & 0.247 \\
\hline & GSDMB & rs2305480 & $17 q 21.1$ & G & 1.03 & & 0.13 & 0.817 & 1.000 \\
\hline & GSDMA & rs3894194 & $17 q 21.1$ & G & 1.02 & 0.88 & 0.69 & 0.846 & 1.000 \\
\hline Meta-analysis $^{a}$ & Gene & SNP & Locus & Effect Allele & OR & $1^{2}$ & & P-value $e^{c, d}$ & Adj P-value \\
\hline \multirow[t]{7}{*}{ (710 cases, 7321 controls) } & IL1RL1 & rs10197862 ${ }^{f}$ & $2 q 12.1$ & A & 1.23 & 70 & & 0.006 & 0.042 \\
\hline & TSLP & rs18372539 & $5 q 22.1$ & $C$ & 1.01 & 45 & & 0.910 & 1.000 \\
\hline & RAD50 & $r s 2244012^{f}$ & $5 q 31.1$ & G & 1.05 & 0 & & 0.447 & 1.000 \\
\hline & IL13 & rs1295686 ${ }^{f}$ & $5 q 31.1$ & $\mathbf{T}$ & 1.19 & 0 & & 0.006 & 0.043 \\
\hline & C11orf30-LRRC32 & rs7130588 & $11 \mathrm{q} 13.5$ & G & 1.23 & 0 & & 0.001 & 0.005 \\
\hline & GSDMB & rs $2305480^{f}$ & $17 q 21.1$ & G & 1.17 & 27 & & 0.018 & 0.125 \\
\hline & GSDMA & rs3894194f & $17 q 21.1$ & $A$ & 1.10 & 57 & & 0.113 & 0.794 \\
\hline
\end{tabular}

Abbreviations: NHGRI-EBI National Human Genome Research Institute - European Bioinformatics Institute; SNP single nucleotide polymorphism; GWAS genomewide association study; NHW Non-Hispanic Whites; AA African American; OR odds ratio of the effect allele; Rsq estimation of imputation quality; Freq frequency of effect allele; $l^{2}$ heterogeneity index; ${ }^{a}$ Each population was run as an independent analysis, and then combined in the meta-analysis: ${ }^{b}$ Logistic regression based on case control status; ${ }^{\mathrm{C}}$ Fixed effect meta-analysis weighted by inverse variance. ${ }^{\mathrm{d}}$ Adjusted for sex, genetic ancestry. ${ }^{\mathrm{e}}$ Bonferroni correction for seven tests, SNPs with adjusted $\mathrm{p}<0.05$ in Bold. ${ }^{f}$ SNP is in the reported gene, ${ }^{g}$ SNP is near the reported gene

[68]. GSDMA is along with GSDMB and ORMDL3 part of the complex 17q21.1 locus, more research is needed to understand the specific interactions of variants in this region and their role in asthma pathobiology [69].

There was one novel genome-wide significant SNP associated with childhood asthma in the GWAS, rs59289606, an intron variant in the protein-coding gene KIAA1958 at locus 9q32; this SNP is imputed with Rsq 0.38 , which meets our criteria for imputation quality. KIAA1958 has not been previously associated with disease pathogenesis [70]. In the AA population, variants of interest were found in FLJ12825 and PHF14. FLJ12825 is a non-coding RNA, and PHF14 is a protein coding gene important in regulation of mesenchymal cell proliferation specific to lung fibrosis, that has also been described in newborn respiratory failure and newborn pulmonary hypertension [71, 72]. Meta-analysis identified a region of interest in SCHIP1 and its read-through transcript IQCJ-SCHIP1. SCHIP1 has been reported along with $I L 12 A$ as a potential systemic sclerosis gene which functions in immune regulation via $\mathrm{T}$ cell activity [73].

\section{Limitations}

This childhood asthma GWAS used a cohort of adult smokers at risk for COPD. It is underpowered relative to the large-scale asthma GWAS that have recently been published. However, our objective was not to run a novel asthma GWAS; rather, the goal of this investigation was to examine self-reported asthma in a population of adult smokers at risk for COPD. Ideally, we would have been able to compare this self-reported diagnosis of childhood asthma to a gold-standard diagnosis, such as childhood spirometry or medical records, but this primary data in this cohort of older adults is not available. Notably, when compared to clinical diagnosis, questionnaire reported asthma history has been shown to have relatively good agreement and reliability over time [74-76]. It would have additionally been valuable to use medical records to assess asthma treatment and control; however, 
we note that many of these subjects had childhood asthma prior to the widespread use of inhaled corticosteroids in the US. Additionally, asthma treatment will not impact the patients' genotype, so the objectivity of that measure is maintained. Since COPDGene includes smokers, we were not able to assess COPD risk among non-smokers; given that this investigation was focused on a population with a high COPD risk, including only smokers is reasonable.

The assessed list of known asthma variants were selected from 600 asthma associations published in the NHGRI-EBI GWAS catalog, where only eight independent SNPs were reported in more than one study. An additional set of five pediatric asthma GWAS SNPs from the TAGC was also examined. We acknowledge that alternative lists of established asthma SNPs could be proposed. It is notable that the established asthma variant list was largely composed of SNPs from European American or NHW populations, and thus the lack of associations in the AA population is not unexpected. This also explains why the combined NHW and AA meta-analysis did not improve power to detect associations for some of the SNPs. It would have been desirable to include other populations with alternative genetic heritage, but COPDGene is limited to NHW and AA subjects.

\section{Conclusions}

Self-report of childhood asthma in adult smokers from COPDGene identifies a meaningful population who demonstrate the demographic, clinical, and genetic characteristics known to associate with childhood asthma. Compared to subjects who never had asthma, self-reported childhood asthmatics were younger, more likely to be of AA race, and had increased odds of COPD. We showed associations with known asthma loci in IL1RL1, IL13, LINC01149, near GSDMB, and in the C11orf30-LRRC32 region. This GWAS identified a new variant in KIAA1958 associated with childhood asthma in NHWs. This study will enhance future genetic epidemiology research in early-life asthmatics at risk for COPD and therefore ACO, by establishing the validity of self-reported asthma in the research setting. This study emphasizes that clinicians need to consider childhood asthma when assessing patients at increased risk for COPD, and that patient self-report is a reliable method of defining ACO.

\section{Additional files}

Additional file 1: Figure S1. Subject classification. Figure S2. QQ-plot and Manhattan plot of childhood asthma GWAS SNPs in non-Hispanic Whites. Figure S3. QQ-plot and Manhattan plot of childhood asthma GWAS SNPs in African Americans. Figure S4. QQ-plot and Manhattan plot of childhood asthma GWAS SNPS from meta-analysis of NHW and AA subjects. Figure S5. LocusZoom Plots of childhood asthma nonHispanic white GWAS variants in PDZD2. Figure S6. LocusZoom Plots of childhood asthma African American GWAS variants in regions of interest in FL12825 and PHF14. Figure S7. In non-Hispanic whites the childhood asthma GWAS found association with the known asthma genes ILIRL1 ( rs10197862, adj $p=0.011$ ) and GSDMB ( $r$ 2305480, adj $p=0.060$ ). Figure S8. Meta-analysis of NHW and AA subjects in this study found association with a known asthma variants in IL13 (rs1295686) and near the C11orf30-LRRC32 region (rs7130588). Table S1. Associations with TAGC Pediatric Asthma GWAS SNPs. (PDF 977 kb)

\section{Abbreviations}

AA: African American; ACO: Asthma-COPD overlap; Cl: Confidence interval; COPD: Chronic obstructive pulmonary disease; $\mathrm{FEV}_{1}$ : Forced expiratory volume in the first second; FVC: Forced vital capacity; GWAS: Genome-Wide Association Study; LD: Linkage disequilibrium; MAF: Minor allele frequency; NHGRI-EBI: National Human Genome Research Institute - European Bioinformatics Institute; NHW: Non-Hispanic white; OR: Odds ratio; PC: Principal components; QQ: Quantile-Quantile; SE: Standard error; SNP: Single nucleotide polymorphism; TAGC: Trans-National Asthma Genetic Consortium; TH2: T-helper cell type 2

\section{Acknowledgements}

COPDGene ${ }^{\oplus}$ Investigators Core Units: Administrative Center: James D. Crapo, MD (PI); Edwin K. Silverman, MD, PhD (PI); Barry J. Make, MD; Elizabeth A. Regan, MD, PhD. Genetic Analysis Center: Terri Beaty, PhD; Ferdouse Begum, PhD; Peter J. Castaldi, MD, MSc; Michael Cho, MD; Dawn L. DeMeo, MD, MPH; Adel R. Boueiz, MD; Marilyn G. Foreman, MD, MS; Eitan Halper-Stromberg; Lystra P. Hayden, MD, MMSc; Craig P. Hersh, MD, MPH; Jacqueline Hetmanski, MS, MPH; Brian D. Hobbs, MD; John E. Hokanson, MPH, PhD; Nan Laird, PhD; Christoph Lange, PhD; Sharon M. Lutz, PhD; Merry-Lynn McDonald, PhD; Margaret M. Parker, PhD; Dandi Qiao, PhD; Elizabeth A. Regan, MD, PhD; Edwin K. Silverman, MD, PhD; Emily S. Wan, MD; Sungho Won, Ph.D.; Phuwanat Sakornsakolpat, M.D.; Dmitry Prokopenko, Ph.D. Imaging Center: Mustafa Al Qaisi, MD; Harvey O. Coxson, PhD; Teresa Gray; MeiLan K. Han, MD, MS; Eric A. Hoffman, PhD; Stephen Humphries, PhD; Francine L. Jacobson, MD, MPH; Philip F. Judy, PhD; Ella A. Kazerooni, MD; Alex Kluiber; David A. Lynch, MB; John D. Newell, Jr., MD; Elizabeth A. Regan, MD, PhD; James C. Ross, PhD; Raul San Jose Estepar, PhD; Joyce Schroeder, MD; Jered Sieren; Douglas Stinson; Berend C. Stoel, PhD; Juerg Tschirren, PhD; Edwin Van Beek, MD, PhD; Bram van Ginneken, PhD; Eva van Rikxoort, PhD; George Washko, MD; Carla G. Wilson, MS. PFT QA Center, Salt Lake City, UT: Robert Jensen, PhD. Data Coordinating Center and Biostatistics, National Jewish Health, Denver, CO: Douglas Everett, PhD; Jim Crooks, PhD; Camille Moore, PhD; Matt Strand, PhD; Carla G. Wilson, MS. Epidemiology Core, University of Colorado Anschutz Medical Campus, Aurora, CO: John E. Hokanson, MPH, PhD; John Hughes, PhD; Gregory Kinney, MPH, PhD; Sharon M. Lutz, PhD; Katherine Pratte, MSPH; Kendra A. Young, PhD. Mortality Adjudication Core: Surya Bhatt, MD; Jessica Bon, MD; MeiLan K. Han, MD, MS; Barry Make, MD; Carlos Martinez, MD, MS; Susan Murray, ScD; Elizabeth Regan, MD; Xavier Soler, MD; Carla G. Wilson, MS. Biomarker Core: Russell P. Bowler, MD, PhD; Katerina Kechris, PhD; Farnoush Banaei-Kashani, Ph.D.

COPDGene ${ }^{\oplus}$ Investigators Clinical Centers: Ann Arbor VA: Jeffrey L. Curtis, MD; Carlos H. Martinez, MD, MPH; Perry G. Pernicano, MD. Baylor College of Medicine, Houston, TX: Nicola Hanania, MD, MS; Philip Alapat, MD; Mustafa Atik, MD; Venkata Bandi, MD; Aladin Boriek, PhD; Kalpatha Guntupalli, MD; Elizabeth Guy, MD; Arun Nachiappan, MD; Amit Parulekar, MD. Brigham and Women's Hospital, Boston, MA: Dawn L. DeMeo, MD, MPH; Craig Hersh, MD, MPH; Francine L. Jacobson, MD, MPH; George Washko, MD. Columbia University, New York, NY: R. Graham Barr, MD, DrPH; John Austin, MD; Belinda D'Souza, MD; Gregory D.N. Pearson, MD; Anna Rozenshtein, MD, MPH, FACR; Byron Thomashow, MD. Duke University Medical Center, Durham, NC: Neil Maclntyre, Jr., MD; H. Page McAdams, MD; Lacey Washington, MD. HealthPartners Research Institute, Minneapolis, MN: Charlene McEvoy, MD, MPH; Joseph Tashjian, MD. Johns Hopkins University, Baltimore, MD: Robert Wise, MD; Robert Brown, MD; Nadia N. Hansel, MD, MPH; Karen Horton, MD; Allison Lambert, MD, MHS; Nirupama Putcha, MD, MHS. Los Angeles Biomedical Research Institute at Harbor UCLA Medical Center, Torrance, CA: Richard Casaburi, PhD, MD; Alessandra Adami, PhD; Matthew Budoff, MD; Hans Fischer, MD; Janos Porszasz, MD, PhD; Harry Rossiter, PhD; William Stringer, MD. Michael E. DeBakey VAMC, Houston, TX: Amir Sharafkhaneh, MD, PhD; Charlie Lan, DO. Minneapolis VA: Christine Wendt, MD; Brian Bell, MD. 
Morehouse School of Medicine, Atlanta, GA: Marilyn G. Foreman, MD, MS; Eugene Berkowitz, MD, PhD; Gloria Westney, MD, MS. National Jewish Health, Denver, CO: Russell Bowler, MD, PhD; David A. Lynch, MB. Reliant Medical Group, Worcester, MA: Richard Rosiello, MD; David Pace, MD. Temple University, Philadelphia, PA: Gerard Criner, MD; David Ciccolella, MD; Francis Cordova, MD; Chandra Dass, MD; Gilbert D'Alonzo, DO; Parag Desai, MD; Michael Jacobs, PharmD; Steven Kelsen, MD, PhD; Victor Kim, MD; A. James Mamary, MD; Nathaniel Marchetti, DO; Aditi Satti, MD; Kartik Shenoy, MD; Robert M. Steiner, MD; Alex Swift, MD; Irene Swift, MD; Maria Elena Vega-Sanchez, MD. University of Alabama, Birmingham, AL: Mark Dransfield, MD; William Bailey, MD; Surya Bhatt, MD; Anand lyer, MD; Hrudaya Nath, MD; J. Michael Wells, MD. University of California, San Diego, CA: Joe Ramsdell, MD; Paul Friedman, MD; Xavier Soler, MD, PhD; Andrew Yen, MD. University of lowa, lowa City, IA: Alejandro P. Comellas, MD; Karin F. Hoth, PhD; John Newell, Jr., MD; Brad Thompson, MD. University of Michigan, Ann Arbor, MI: MeiLan K. Han, MD, MS; Ella Kazerooni, MD; Carlos H. Martinez, MD, MPH. University of Minnesota, Minneapolis, MN: Joanne Billings, MD; Abbie Begnaud, MD; Tadashi Allen, MD. University of Pittsburgh, Pittsburgh, PA: Frank Sciurba, MD; Jessica Bon, MD; Divay Chandra, MD, MSc; Carl Fuhrman, MD; Joel Weissfeld, MD, MPH. University of Texas Health Science Center at San Antonio, San Antonio, TX: Antonio Anzueto, MD; Sandra Adams, MD; Diego Maselli-Caceres, MD; Mario E. Ruiz, MD.

\section{Funding}

Supported by National Institutes of Health (NIH) grants K23HL136851 (LPH), K12HL120004 (EKS), R01HL113264 (EKS and MHC), U01HL089856 (EKS), U01HL089897 (JD Crappo), R01HL130512 (CPH), R01HL125583 (CPH), P01HL105339 (EKS). The COPDGene Study (NCT00608764) is also supported by the COPD Foundation through contributions made to an Industry Advisory Board comprised of AstraZeneca, Boehringer Ingelheim, GlaxoSmithKline, Novartis, Pfizer, Siemens and Sunovion. Neither the NIH nor the Industry Advisory Board had a role in the study design, data collection, data analysis, interpretation of the data, writing of the report or the decision to submit the paper for publication. The content is solely the responsibility of the authors and does not necessarily represent the official views of the National Heart, Lung, And Blood Institute or the National Institutes of Health.

\section{Availability of data and materials}

COPDGene datasets are publicly available (dbGaP accession number phs000179.v1.p1).

\section{Authors' contributions}

$\mathrm{LPH}, \mathrm{MHC}, \mathrm{BAR}, \mathrm{THB}, \mathrm{EKS}, \mathrm{CPH}$ contributed to data analysis and interpretation, critical revision of the article, and final approval of the version to be published; they all agree to be accountable for all aspects of the work. $\mathrm{LPH}, \mathrm{MHC}, \mathrm{BAR}$, $\mathrm{THB}, \mathrm{EKS}, \mathrm{CPH}$ contributed to the study conception and design. EKS, CPH contributed to the acquisition of data. $\mathrm{LPH}, \mathrm{CPH}$ contributed to drafting of the submitted article. All authors read and approved the final manuscript.

\section{Ethics approval and consent to participate}

This study was conducted in accordance with the amended Declaration of Helsinki. This study obtained approval from the Institutional Review Board at Brigham and Women's Hospital and at each of the twenty-one clinical sites. All participants provided written informed consent for their medical data to be used prior to taking part in the study.

Clinical Center and IRB protocol numbers:

Ann Arbor VA, Ann Arbor, MI (PCC 2008-110732).

Baylor College of Medicine, Houston, TX (H-22209).

Brigham and Women's Hospital, Boston, MA (2007-P-000554/2; BWH).

Columbia University, New York, NY (IRB-AAAC9324).

Duke University Medical Center, Durham, NC (Pro00004464).

Health Partners Research Foundation, Minneapolis, MN (07-127).

Johns Hopkins University, Baltimore, MD (NA_00011524).

Los Angeles Biomedical Research Institute at Harbor UCLA Medical Center,

Los Angeles, CA (12756-01).

Michael E. DeBakey VAMC, Houston, TX (H-22202).

Minneapolis VA, Minneapolis, MN (4128-A).

Morehouse School of Medicine, Atlanta, GA (07-1029).

National Jewish Health, Denver, CO (HS-1883a).

Reliant Medical Group, Worcester, MA (1143).

Temple University, Philadelphia, PA (11369).

University of Alabama, Birmingham, AL (FO70712014).
University of California, San Diego, CA (70876)

University of lowa, lowa City, IA (200710717).

University of Michigan, Ann Arbor, MI (HUM00014973).

University of Minnesota, Minneapolis, MN (0801 M24949).

University of Pittsburgh, Pittsburgh, PA (PRO07120059).

University of Texas Health Science Center at San Antonio, San Antonio, TX (HSC20070644H).

\section{Competing interests}

C.P. Hersh reports personal fees from AstraZeneca, grants from Boehringer Ingelheim, personal fees from Mylan, personal fees from Concert

Pharmaceuticals, all of which are outside the submitted work. In the past three years, E.K. Silverman received honoraria from Novartis for Continuing Medical Education Seminars and grant and travel support from GlaxoSmithKline unrelated to this manuscript. M.H. Cho has received grant support from GlaxoSmithKline. Authors L.P. Hayden, B.A. Raby, and T.H. Beaty have no conflicts of interest to disclose.

\section{Publisher's Note}

Springer Nature remains neutral with regard to jurisdictional claims in published maps and institutional affiliations.

\section{Author details}

'Division of Respiratory Diseases, Boston Children's Hospital, Boston, MA USA. ${ }^{2}$ Channing Division of Network Medicine, Brigham and Women's Hospital, 181 Longwood Avenue, Boston, MA 02115, USA. ${ }^{3}$ Division of Pulmonary and Critical Care Medicine, Brigham and Women's Hospital, Boston, MA, USA. ${ }^{4}$ Bloomberg School of Public Health, Johns Hopkins University, Baltimore, MD, USA.

Received: 18 July 2018 Accepted: 12 September 2018

Published online: 29 October 2018

\section{References}

1. Asthma Fact Sheet. http://www.who.int/mediacentre/factsheets/fs307/en/. Accessed Jan. 23, 2018.

2. Welter D, MacArthur J, Morales J, Burdett T, Hall P, Junkins H, et al. The NHGRI GWAS catalog, a curated resource of SNP-trait associations. Nucleic Acids Res. 2014:42:D1001-6.

3. The NHGRI-EBI GWAS Catalog of published genome-wide association studies. . https://www.ebi.ac.uk/gwas/. Accessed Sept 28, 2017.

4. Moffatt MF, Kabesch M, Liang L, Dixon AL, Strachan D, Heath S, et al. Genetic variants regulating ORMDL3 expression contribute to the risk of childhood asthma. Nature. 2007:448:470-3.

5. Moffatt MF, Gut IG, Demenais F, Strachan DP, Bouzigon E, Heath S, et al. A large-scale, consortium-based genomewide association study of asthma. N Engl J Med. 2010;363:1211-21.

6. Forno E, Lasky-Su J, Himes B, Howrylak J, Ramsey C, Brehm J, et al. Genomewide association study of the age of onset of childhood asthma. J Allergy Clin Immunol 2012;130:83-90 e84.

7. Bonnelykke K, Sleiman P, Nielsen K, Kreiner-Moller E, Mercader JM, Belgrave $D$, et al. A genome-wide association study identifies CDHR3 as a susceptibility locus for early childhood asthma with severe exacerbations. Nat Genet. 2014:46:51-5.

8. Ullemar V, Magnusson PK, Lundholm C, Zettergren A, Melen E, Lichtenstein $P$, et al. Heritability and confirmation of genetic association studies for childhood asthma in twins. Allergy. 2016;71:230-8.

9. Koeppen-Schomerus G, Stevenson J, Plomin R. Genes and environment in asthma: a study of 4 year old twins. Arch Dis Child. 2001;85:398-400.

10. van Beijsterveldt CE, Boomsma DI. Genetics of parentally reported asthma, eczema and rhinitis in 5-yr-old twins. Eur Respir J. 2007;29:516-21.

11. McGeachie MJ. Childhood asthma is a risk factor for the development of chronic obstructive pulmonary disease. Curr Opin Allergy Clin Immunol. 2017:17:104-9.

12. McGeachie MJ, Yates KP, Zhou X, Guo F, Sternberg AL, Van Natta ML, et al. Patterns of growth and decline in lung function in persistent childhood asthma. N Engl J Med. 2016;374:1842-52.

13. Lange P, Parner J, Vestbo J, Schnohr P, Jensen G. A 15-year follow-up study of ventilatory function in adults with asthma. N Engl J Med. 1998;339:1194-200.

14. Svanes C, Sunyer J, Plana E, Dharmage S, Heinrich J, Jarvis D, et al. Early life origins of chronic obstructive pulmonary disease. Thorax. 2010;65:14-20. 
15. Woodruff PG, van den Berge M, Boucher RC, Brightling C, Burchard EG, Christenson SA, et al. American Thoracic Society/National Heart, Lung, and Blood Institute asthma-chronic obstructive pulmonary disease overlap workshop report. Am J Respir Crit Care Med. 2017;196:375-81.

16. Hayden LP, Hobbs BD, Cohen RT, Wise RA, Checkley W, Crapo JD, et al. Childhood pneumonia increases risk for chronic obstructive pulmonary disease: the COPDGene study. Respir Res. 2015;16:115.

17. Hardin M, Silverman EK, Barr RG, Hansel NN, Schroeder JD, Make BJ, et al. The clinical features of the overlap between COPD and asthma. Respir Res. 2011;12:127

18. Hardin M, Foreman M, Dransfield MT, Hansel N, Han MK, Cho MH, et al. Sexspecific features of emphysema among current and former smokers with COPD. Eur Respir J. 2016:47:104-12.

19. Diaz AA, Hardin ME, Come CE, San Jose Estepar R, Ross JC, Kurugol S, et al. Childhood-onset asthma in smokers. Association between CT measures of airway size, lung function, and chronic airflow obstruction. Ann Am Thorac Soc. 2014;11:1371-8.

20. Hayden LP, Hardin ME, Qiu W, Lynch DA, Strand MJ, van Beek EJ, et al. Asthma is a risk factor for respiratory exacerbations without increased rate of lung function decline: five-year follow-up in adult smokers from the COPDGene study. Chest. 2018;153:368-77.

21. Kesten S, Dzyngel B, Chapman KR, Zamel N, Tarlo S, Malo JL, et al. Defining the asthma phenotype for the purpose of genetic analysis. J Asthma. 1997;34:483-91.

22. Kauppi $P$, Laitinen LA, Laitinen $H$, Kere J, Laitinen $T$. Verification of selfreported asthma and allergy in subjects and their family members volunteering for gene mapping studies. Respir Med. 1998;92:1281-8.

23. Sin DD, Miravitlles M, Mannino DM, Soriano JB, Price D, Celli BR, et al. What is asthma-COPD overlap syndrome? Towards a consensus definition from a round table discussion. Eur Respir J. 2016;48:664-73.

24. Demenais F, Margaritte-Jeannin P, Barnes KC, Cookson WOC, Altmuller J, Ang $W$, et al. Multiancestry association study identifies new asthma risk loci that colocalize with immune-cell enhancer marks. Nat Genet. 2018;50:42-53.

25. Regan EA, Hokanson JE, Murphy JR, Make B, Lynch DA, Beaty TH, et al. Genetic epidemiology of COPD (COPDGene) study design. COPD. 2010;7:32-43.

26. COPDGene, Phase 1 Study Documents. http://www.copdgene.org/phase-1study-documents. Accessed Mar. 13, 2015.

27. Ferris BG. Epidemiology standardization project (American Thoracic Society). Am Rev Respir Dis. 1978;118:1-120.

28. Cho MH, Boutaoui N, Klanderman BJ, Sylvia JS, Ziniti JP, Hersh CP, et al. Variants in FAM13A are associated with chronic obstructive pulmonary disease. Nat Genet. 2010;42:200-2.

29. Cho MH, McDonald ML, Zhou X, Mattheisen M, Castaldi PJ, Hersh CP, et al. Risk loci for chronic obstructive pulmonary disease: a genome-wide association study and meta-analysis. Lancet Respir Med. 2014;2:214-25.

30. Genomes Project C, Abecasis GR, Auton A, Brooks LD, DePristo MA, Durbin RM, et al. An integrated map of genetic variation from 1,092 human genomes. Nature. 2012;491:56-65.

31. Howie B, Fuchsberger C, Stephens M, Marchini J, Abecasis GR. Fast and accurate genotype imputation in genome-wide association studies through pre-phasing. Nat Genet. 2012;44:955-9.

32. Li Y, Byrnes AE, Li M. To identify associations with rare variants, just WHalT: weighted haplotype and imputation-based tests. Am J Hum Genet. 2010;87: 728-35

33. Marenholz I, Esparza-Gordillo J, Ruschendorf F, Bauerfeind A, Strachan DP, Spycher BD, et al. Meta-analysis identifies seven susceptibility loci involved in the atopic march. Nat Commun. 2015;6:8804.

34. Rabe KF, Hurd S, Anzueto A, Barnes PJ, Buist SA, Calverley P, et al. Global strategy for the diagnosis, management, and prevention of chronic obstructive pulmonary disease: GOLD executive summary. Am J Respir Crit Care Med. 2007;176:532-55.

35. Purcell S, Neale B, Todd-Brown K, Thomas L, Ferreira MA, Bender D, et al. PLINK: a tool set for whole-genome association and population-based linkage analyses. Am J Hum Genet. 2007;81:559-75.

36. Hoggart CJ, Clark TG, De lorio M, Whittaker JC, Balding DJ. Genome-wide significance for dense SNP and resequencing data. Genet Epidemiol. 2008; 32:179-85.

37. Risch N, Merikangas $K$. The future of genetic studies of complex human diseases. Science. 1996;273:1516-7.

38. Yu K, Wang Z, Li Q, Wacholder S, Hunter DJ, Hoover RN, et al. Population substructure and control selection in genome-wide association studies. PLoS One. 2008;3:e2551.
39. Evangelou E, loannidis JP. Meta-analysis methods for genome-wide association studies and beyond. Nat Rev Genet. 2013;14:379-89.

40. Ferreira MA, Matheson MC, Duffy DL, Marks GB, Hui J, Le Souef $P$, et al. Identification of IL6R and chromosome 11q13.5 as risk loci for asthma. Lancet. 2011;378:1006-14.

41. Yan Q, Brehm J, Pino-Yanes M, Forno E, Lin J, Oh SS, et al. A meta-analysis of genome-wide association studies of asthma in Puerto Ricans. Eur Respir J. 2017;49.

42. Barreto-Luis A, Pino-Yanes M, Corrales A, Campo P, Callero A, AcostaHerrera $M$, et al. Genome-wide association study in Spanish identifies ADAM metallopeptidase with thrombospondin type 1 motif, 9 (ADAMTS9), as a novel asthma susceptibility gene. J Allergy Clin Immunol. 2016;137:964-6.

43. Hirota T, Takahashi A, Kubo M, Tsunoda T, Tomita K, Doi S, et al. Genomewide association study identifies three new susceptibility loci for adult asthma in the Japanese population. Nat Genet. 2011;43:893-6.

44. Torgerson DG, Ampleford EJ, Chiu GY, Gauderman WJ, Gignoux CR, Graves $P E$, et al. Meta-analysis of genome-wide association studies of asthma in ethnically diverse north American populations. Nat Genet. 2011;43:887-92.

45. Ferreira MA, Matheson MC, Tang CS, Granell R, Ang W, Hui J, et al. Genomewide association analysis identifies 11 risk variants associated with the asthma with hay fever phenotype. J Allergy Clin Immunol. 2014;133:1564-71.

46. Pickrell JK, Berisa T, Liu JZ, Segurel L, Tung JY, Hinds DA. Detection and interpretation of shared genetic influences on 42 human traits. Nat Genet. 2016:48:709-17.

47. Almoguera B, Vazquez L, Mentch F, Connolly J, Pacheco JA, Sundaresan AS, et al. Identification of four novel loci in asthma in European American and African American populations. Am J Respir Crit Care Med. 2017;195:456-63.

48. Li X, Howard TD, Zheng SL, Haselkorn T, Peters SP, Meyers DA, et al. Genome-wide association study of asthma identifies RAD50-IL13 and HLADR/DQ regions. J Allergy Clin Immunol. 2010;125:328-335 e311.

49. Weidinger S, Willis-Owen SA, Kamatani $Y$, Baurecht $H$, Morar N, Liang L, et al. A genome-wide association study of atopic dermatitis identifies loci with overlapping effects on asthma and psoriasis. Hum Mol Genet. 2013;22:4841-56.

50. Galanter JM, Gignoux CR, Torgerson DG, Roth LA, Eng C, Oh SS, et al. Genome-wide association study and admixture mapping identify different asthma-associated loci in Latinos: the Genes-environments \& Admixture in Latino Americans study. J Allergy Clin Immunol. 2014;134:295-305.

51. Morris AP. Transethnic meta-analysis of genomewide association studies. Genet Epidemiol. 2011;35:809-22.

52. Martinez FD. Early-life origins of chronic obstructive pulmonary disease. N Engl J Med. 2016:375:871-8.

53. Hayden LP, Hardin ME, Qiu W, Lynch DA, Strand MJ, van Beek EJ, et al. Asthma is a risk factor for respiratory exacerbations without increased rate of lung function decline: five-year follow-up in adult smokers from the COPDGene study. Chest. 2017.

54. Bujarski S, Parulekar AD, Sharafkhaneh A, Hanania NA. The asthma COPD overlap syndrome (ACOS). Curr Allergy Asthma Rep. 2015;15:509.

55. Global Initiative for Asthma (GINA) Global Initiative for Chronic Obstructive Lung Disease (GOLD). Diagnosis of Diseases of Chronic Airflow Limitation: Asthma COPD and Asthma-COPD Overlap Syndrome (ACOS). 2015.

56. Bonten TN, Kasteleyn MJ, de Mutsert R, Hiemstra PS, Rosendaal FR, Chavannes NH, et al. Defining asthma-COPD overlap syndrome: a population-based study. Eur Respir J. 2017:49.

57. Global Initiative for Asthma (GINA). 2017 GINA Report, Global strategy for asthma management and prevention.

58. Barrecheguren $M$, Roman-Rodriguez $M$, Miravitlles $M$. Is a previous diagnosis of asthma a reliable criterion for asthma-COPD overlap syndrome in a patient with COPD? Int J Chron Obstruct Pulmon Dis. 2015;10:1745-52.

59. Liu Z, Li P, Wang J, Fan Q, Yan P, Zhang X, et al. A meta-analysis of IL-13 polymorphisms and pediatric asthma risk. Med Sci Monit. 2014;20:2617-23.

60. Tamari M, Tanaka S, Hirota T. Genome-wide association studies of allergic diseases. Allergol Int. 2013:62:21-8.

61. Ramasamy A, Kuokkanen M, Vedantam S, Gajdos ZK, Couto Alves A, Lyon $H N$, et al. Genome-wide association studies of asthma in population-based cohorts confirm known and suggested loci and identify an additional association near HLA. PLOS One. 2012:7:e44008.

62. Gudbjartsson DF, Bjornsdottir US, Halapi E, Helgadottir A, Sulem P, Jonsdottir GM, et al. Sequence variants affecting eosinophil numbers associate with asthma and myocardial infarction. Nat Genet. 2009;41:342-7. 
63. Inoue H, Ito I, Niimi A, Matsumoto H, Oguma T, Tajiri T, et al. Association of interleukin 1 receptor-like 1 gene polymorphisms with eosinophilic phenotype in Japanese adults with asthma. Respir Investig. 2017;55:338-47.

64. Gordon ED, Palandra J, Wesolowska-Andersen A, Ringel L, Rios CL, Lachowicz-Scroggins ME, et al. IL1RL1 asthma risk variants regulate airway type 2 inflammation. JCl Insight. 2016;1:e87871.

65. Jenuth JP. The NCBI. Publicly available tools and resources on the web. Methods Mol Biol. 2000;132:301-12.

66. Panganiban RA, Sun M, Dahlin A, Park HR, Kan M, Himes BE, et al. A functional splicing variant associated with decreased asthma risk abolishes the ability of gasdermin B (GSMDB) to induce epithelial cell pyroptosis. J Allergy Clin Immunol. 2018

67. Li X, Ampleford EJ, Howard TD, Moore WC, Li H, Busse WW, et al. The C11 orf30-LRRC32 region is associated with total serum lgE levels in asthmatic patients. J Allergy Clin Immunol. 2012;129:575-8 578 e571-579.

68. Hwang SS, Jang SW, Lee KO, Kim HS, Lee GR. RHS6 coordinately regulates the Th2 cytokine genes by recruiting GATA3, SATB1, and IRF4. Allergy. 2017; 72:772-82.

69. Stein MM, Thompson EE, Schoettler N, Helling BA, Magnaye KM, Stanhope C, et al. A decade of research on the 17q12-21 asthma locus: piecing together the puzzle. J Allergy Clin Immunol. 2018.

70. Kojima KK, Jurka J. Crypton transposons: identification of new diverse families and ancient domestication events. Mob DNA. 2011;2:12

71. Kitagawa M, Takebe A, Ono Y, Imai T, Nakao K, Nishikawa S, et al. Phf14, a novel regulator of mesenchyme growth via platelet-derived growth factor (PDGF) receptor-alpha. J Biol Chem. 2012;287:27983-96.

72. Huang Q, Zhang L, Wang Y, Zhang C, Zhou S, Yang G, et al. Depletion of PHF14, a novel histone-binding protein gene, causes neonatal lethality in mice due to respiratory failure. Acta Biochim Biophys Sin Shanghai. 2013:45:622-33.

73. Jin J, Chou C, Lima M, Zhou D, Zhou X. Systemic sclerosis is a complex disease associated mainly with immune regulatory and inflammatory genes. Open Rheumatol J. 2014;8:29-42.

74. Toren K, Brisman J, Jarvholm B. Asthma and asthma-like symptoms in adults assessed by questionnaires. A literature review. Chest. 1993;104:600-8.

75. Tisnado DM, Adams JL, Liu H, Damberg CL, Chen WP, Hu FA, et al. What is the concordance between the medical record and patient self-report as data sources for ambulatory care? Med Care. 2006;44:132-40.

76. Mirabelli MC, Beavers SF, Flanders WD, Chatterjee AB. Reliability in reporting asthma history and age at asthma onset. J Asthma. 2014;51:956-63.

Ready to submit your research? Choose BMC and benefit from:

- fast, convenient online submission

- thorough peer review by experienced researchers in your field

- rapid publication on acceptance

- support for research data, including large and complex data types

- gold Open Access which fosters wider collaboration and increased citations

- maximum visibility for your research: over $100 \mathrm{M}$ website views per year

At BMC, research is always in progress.

Learn more biomedcentral.com/submissions 